\section{Debate: Impact measurement and social public procurement}

\section{Irene Bengo}

After the 2008 economic crisis, many administrations at different levels, pressed by the need to cut public spending and contain public debt and deficits, tried new forms of social public procurement with the aim of creating direct and indirect social value (Furneaux and Barraket, 2014). The effectiveness of these policies, the ambitiousness of their goals, and their potential diffusion were often limited by the need to monitor and evaluate results and social impacts.

This reflection is particularly relevant today, when many external factors make social impact measurement inevitable and extensive. Attempts by public administrations to reengineer their procurement schemes to be outcome-based is consistent with the emergence and acceleration of social impact finance and the outcome-based, or pay-for-results financing models (Arena et al., 2016).

I began a recent article (with Mario Calderini) with the social impact measurement literature, which discusses the need for common and shared frameworks for social ventures and addresses the lack of consolidated instruments to measure the social value of public administration services (Bengo and Calderini, 2016). We identified three main barriers: measurement standards, measurement data and measurement governance.

The first popular theme in international circles is measurement techniques and, more generally, measurement standards. This debate is essentially summarized in three sub-questions. The first is strictly technical and concerns the contrast between synthetic metrics and descriptive process indicators (Bengo et al., 2016). The second refers to the ability or inability to standardize measurements in advance: should we look for closed indicator systems based on predefined indicator packages or move towards an open system based on guidelines and general reporting? For example, the G8 taskforce on impact finance strongly suggested the second path (Social Impact Investment Taskforce, 2014). The third question concerns the possibility of defining a measurement standard and, specifically, which process should be used to define this standard: de jure, de facto, or with spontaneous coalition instruments between private and public bodies?

The academic literature related to the definition of technological standards shows that this can be achieved by finding a balance between the two extremes of imposition de jure and the spontaneous, de facto, definition of the market. This means intermediate governance tools, public-private coalitions that involve associations, research organizations, individual businesses and public and private financiers, and allowing sufficiently heterogeneous and open standards to be defined but shared and generated through a participatory process (Arena et al., 2018). This would occur without indicator packages but, instead, by defining broad guidelines inspired by principles of information, measurability, clarity and transparency.

Rather than imposing obligations, the public entity should formulate a softgovernance approach to determine measurement standards with a dual role, on one hand, by providing support to less powerful bodies (for example social enterprises) by consolidating specific technical skills and abilities and, on the other hand, by becoming guarantors of balanced and harmonious interests among all the players involved. Specifically, it could direct the participatory process of defining measurement standards and promoting their diffusion via their procurement system renewal, including criteria for measuring social impact.

The second issue in this debate is the availability of data suitable for measurement. The guiding principle should be maintaining a fair balance between an indicator's level of sophistication and the quality of the available data. It is necessary to increase data quality, where quality refers not only to availability but also to homogeneity, inter-operability, and standardization. Not surprisingly, the OECD set up a taskforce to build large international databases for measuring social impact. Public administrations could help build impact measurement databases by investing in the open release of public data, harmonizing the sources, making them inter-operable, and developing public-private partnerships that facilitate the release and integration of private sector data that has a public origin.

Finally, the many of the outcome-based (or pay-for-results) instruments rely on an independent third party that certifies based on prediction, quality and measurability of the 
objectives and, retrospectively, quality and measurability achieved. Therefore, measurement systems that support financial instruments should be based on a 'trust infrastructure': a functional, trusted infrastructure for impact measurement. In this context, the public body could promote the foundation or development of measurement organizations that are compatible with independent third parties.

In conclusion, overcoming these barriers cannot be left exclusively to the public sector, but should take place through a participatory approach with the relevant actors in the social ecosystem, with the aim of harmonizing different stakeholders interests.

\section{References}

Arena, M., Bengo, I., Calderini, M. and Chiodo, V. (2018), Unlocking finance for social tech start-ups: is there a new opportunity space? Technological Forecasting and Social Change, 127, pp. 154-165.
Arena, M., Bengo, I., Calderini, M. and Chiodo, V. (2016), Social impact bonds: blockbuster or flash in a pan? International Journal of Public Administration, 39 , 12, pp. 927-939.

Bengo, I., Arena, M., Azzone, G. and Calderini, M. (2016), Indicators and metrics for social business: a review of current approaches. Journal of Social Entrepreneurship, 7, 1, pp. 1-24.

Bengo, I. and Calderini, M. (2016), Are social impact bonds (SIBs) viable in Italy? A new roadmap. Public Money E Management, 36, 4, pp. 303-306.

Furneaux, C. and Barraket, J. (2014), Purchasing social $\operatorname{good}(\mathrm{s})$ : a definition and typology of social procurement. Public Money $\varepsilon^{\circ}$ Management, 34 , 4. pp. 265-272.

Social Impact Investment Taskforce (2014), Impact Investment: The Invisible Heart of Markets (www.socialimpactinvestment.org).

Irene Bengo is a Researcher in the Department of Management, Economics and Industrial Engineering, Politecnico di Milano, Italy. 